\title{
Vertebral fractures and their association with health-related quality of life, back pain and physical function in older women
}

\author{
Lisa Johansson ${ }^{1,2}$ • Daniel Sundh ${ }^{1}$ - Martin Nilsson ${ }^{1,3}$ • Dan Mellström ${ }^{1,4}$ • \\ Mattias Lorentzon ${ }^{1,4}$ (i)
}

Received: 16 June 2017 / Accepted: 30 October 2017 /Published online: 15 November 2017

(C) The Author(s) 2017. This article is an open access publication

\begin{abstract}
Summary Studies investigating prevalent vertebral fracture (VF) diagnosed using densitometry-based VF assessment (VFA) and associations with physical function, assessed by performance-based measures, are lacking. In this populationbased study of 1027 older women, we found that prevalent VF, identified by VFA, was associated with inferior physical health, back pain and inferior physical function.

Purpose Several studies have investigated the associations between health-related quality of life (HRQL) and back pain with prevalent VF, detected by spine radiographs, but just a few have been population-based and have used vertebral fracture assessment (VFA) for diagnosing VF. The aims of this study were to investigate associations between prevalent VF, detected by VFA, with HRQL, back pain and physical function, and investigate if also mild VFs were associated with these clinical parameters.

Methods One thousand twenty-seven women aged 7580 years participated in this population-based cross-sectional study. VF was identified by VFA using dual-energy X-ray absorptiometry. HRQL was assessed by SF-12, back pain
\end{abstract}

Mattias Lorentzon

mattias.lorentzon@medic.gu.se

1 Geriatric Medicine, Department of Internal Medicine and Clinical Nutrition, Institute of Medicine, University of Gothenburg, Gothenburg, Sweden

2 Department of Orthopaedics, Sahlgrenska University Hospital, Mölndal, Sweden

3 Health and Medical Care, City District Administration of Örgryte-Härlanda, City of Gothenburg, Sweden

4 Geriatric Medicine, Institute of Medicine, The Sahlgrenska Academy, Building K, 6th Floor, Sahlgrenska University Hospital, Mölndal, 43180 Mölndal, Sweden during the past 12 months using a questionnaire, and physical function was tested with one leg standing (OLS), Timed Up and Go (TUG), walking speed, 30-s chair stand test and maximum grip strength.

Results Physical health (Physical Component Summary, PCS), derived from SF-12, was worse $(43.5 \pm 11.3$ vs. 46.2 $\pm 10.5, p<0.001)$ and back pain more frequent in women with any VF than in women without $(69.0$ vs. $59.9 \%, p=$ 0.008). PCS and physical function (OLS, 30-s chair stand test), were significantly worse for mild VF compared to no VF $(43.8 \pm 10.9$ vs. $46.2 \pm 10.5, p<0.001,12.7 \pm 9.9$ vs. 15.3 $\pm 10.4 \mathrm{~s}, p=0.038,10.7 \pm 3.2$ vs. $11.4 \pm 3.4$ times, $p=0.021$, respectively). In multivariable adjusted linear regression models, VF prevalence was associated with PCS $(\beta=-$ $0.079, p=0.007)$, TUG $(\beta=0.067, p=0.021)$, walking speed $(\beta=-0.071, p=0.009)$ and 30 -s chair stand test $(\beta=-0.075$, $p=0.012$ ).

Conclusions In conclusion, prevalent VF, diagnosed by VFA, was associated with inferior physical health, back pain and inferior physical function, indicating VFA is useful for diagnosing clinically relevant vertebral fractures. Also, mild VF was associated with inferior physical health and inferior physical function.

Keywords Back pain $\cdot \mathrm{HRQL} \cdot$ Physical function - Vertebral fracture $\cdot$ Vertebral fracture assessment

\section{Introduction}

Vertebral fractures (VFs) are among the most frequent and serious osteoporotic fractures [1]. Osteoporotic VFs must be diagnosed using spinal imaging, which contributes to that only one in three individuals with osteoporotic VF come to clinical 
attention [2]. In previous studies, the prevalence of VF among women aged 50 years and over has been estimated to $25 \%$ [3].

The global burden of osteoporotic fracture has been estimated and out of a total 9.0 million osteoporotic fractures in the year 2000, 1.4 million were clinical vertebral fractures [4]. The European Vertebral Osteoporosis Study revealed that the prevalence of VF in Sweden (among both men and women) was among the highest in the European countries [5].

VFs are associated with back pain, disability, impaired quality of life, morbidity and mortality [6-8]. In a recent meta-analysis of older osteoporotic patients with and without VFs the physical and mental health-related quality of life (HRQL) was reported to be worse in people with VF [9]. Individuals with an initial VF have a fivefold increased risk to sustain a subsequent VF the first following year than individuals without VF [10]. It is therefore of great importance to diagnose individuals with $\mathrm{VF}$, even the asymptomatic ones, in order to be able to provide appropriate treatment, to decrease the risk of subsequent osteoporotic fractures in the spine or at other sites [11].

Vertebral fracture assessment (VFA) is an established method to detect VF [12-14]. Lateral spine imaging is performed with bone densitometers using single or dual-energy $\mathrm{X}$-ray absorptiometry (DXA) with the benefit of less radiation compared to conventional radiographs [12]. The sensitivity and specificity is high for moderate and severe VF (87-92\% and 93-98\%, respectively) but is lower for mild fractures [13, 15]. However, with improvements of the DXA scanners the last years, also mild fractures can be diagnosed with high accuracy [16]. Thus, VFA is a method that can be applied in conjunction with a standard clinical osteoporosis evaluation, to diagnose VFs with very little additional radiation and at low cost. Most previous studies investigating associations between prevalent VF and quality of life, morbidity and mortality have used conventional spine radiography to identify fractures [6-8]. Among the studies, reporting use of VFA to diagnose prevalent VFs, just a few have been population-based [16-18]. Kanterewicz et al. found a high prevalence (17\%) of minor vertebral deformities and that the prevalence of osteoporosis was higher in women with these deformities than in women without. Waterloo et al. reported that prevalent VF in women was associated with back pain and that the severity of fracture was associated with quality of life, using the selfadministered questionnaire EQ-5D-3 L.

Studies investigating prevalent VF, identified using VFA, and their association with physical function are lacking, and little is known about associations between mild fractures and clinical outcomes. The primary aim of this population-based cross-sectional study was to investigate if prevalent VF, detected by VFA, was associated with quality of life, back pain and physical function in older women, and if VFA is useful for diagnosing clinically relevant VFs. The secondary aim was to assess if also mild VFs were associated with these clinical parameters.

\section{Subjects and methods}

\section{Subjects}

A cross-sectional population-based study was performed with 3030 women between the ages of 75 to 80 years. Women living in Gothenburg or in nearby suburbs were randomly recruited using information in the Swedish national population register between March 2013 and May 2016. A letter of invitation was sent and women were then contacted by telephone. All of the included women were ambulant and could understand Swedish. A questionnaire regarding medication, disease, back pain and physical activity habits was completed by all the participants and physical function tests were performed. Occurrence of VF was investigated by VFA in a cohort of 1053 women from these 3030 women. Due to extreme scoliosis, inadequate image quality and high body mass index $>41.0 \mathrm{~kg} / \mathrm{m}^{2}$ (BMI), 26 women (20, 4, and 2, respectively) were excluded. As a result, the final cohort consisted of 1027 women. All the study participants gave their informed consent and the ethical review board at the University of Gothenburg approved the study. The examinations took place at the Osteoporosis Clinic, at the Geriatric Medicine clinic, Sahlgrenska University Hospital in Mölndal, Sweden.

\section{Physical function tests}

The one-leg standing test (OLS) was performed with eyes opened and arms across the chest [19]. Women were asked to choose which leg they preferred to start with. Time keeping started when the foot was lifted from the ground with flexed knee and ended when the foot touched the floor again, or the arm moved from the chest, if the weight bearing limb moved or when the time reached $30 \mathrm{~s}$. The test was performed twice and the maximum value was used in the analysis.

The Timed Up and Go (TUG) tests mobility and balance [20]. From a sitting position in a chair, which was $45 \mathrm{~cm}$ high and with armrests, the subject rose and walked three meters in normal pace, turned around, walked back and sat down into the chair again. The time for this procedure was recorded. Participants wore footwear of their own choice and walking aids were allowed if needed. The test was repeated once, but then performed with a glass of water in one hand (TUG manual).

The 30-s chair stand test measures lower body strength [21]. The subject sat in a chair, $45 \mathrm{~cm}$ high, with the wrists crossed against the chest, and on a command "go" the participant rose to standing position and then returned to sitting position and repeated this procedure as many times as possible in $30 \mathrm{~s}$.

The gait velocity was recorded with the timed 10-m walk test $[22,23]$. Each participant was instructed to walk $10 \mathrm{~m}$ in a pace they found comfortable. To eliminate the acceleration and deceleration, time keeping started after $2 \mathrm{~m}$ and ended at 
$8 \mathrm{~m}$. The test was repeated twice, and the mean value of the repeated test was recorded in meters per second.

A Saehan hydraulic hand dynamometer (model SH5001; Saehan Corporation, Masan, Korea) was used to measure grip strength in the dominant hand. With the arm resting on a table with the elbow flexed in $90^{\circ}$, two attempts were performed and the average strength, measured in kilogram, was used in the analyses $[24,25]$.

\section{Questionnaires}

A self-reported questionnaire was completed by all the participants including questions regarding medical history, medication, previous fracture, life-style factors influencing the risk of osteoporosis and fractures, health-related quality of life (12item Short Form Health Survey, SF-12), current physical activity (the Physical Activity Scale for the Elderly, PASE), previous back pain the past 12 months (yes/no), and daily calcium intake.

The SF-12 was developed from the Medical Outcomes Study 36-Item Short-Form Health Survey (SF-36) to offer a shorter survey taking less time for the participants to answer [26]. It consists of 12 questions about physical and mental health. The score from SF-12 was weighted and summed and provided a value for physical (Physical Component Summary, PCS) and mental health (Mental Component Summary, MCS) between 0 to 100 , where 0 indicates the lowest level of health and 100 indicates the highest level of health.

The PASE questionnaire assesses physical activity, the last 7 days, in persons 65 years and older [27]. Questions include leisure activities, sport and recreation and are recorded as seldom (1-2 days), sometimes (3-4 days) or often (5-7 days), also taking into account the duration defined as $<1 \mathrm{~h}, 1-2 \mathrm{~h}$, $2-4 \mathrm{~h}$ or $>4 \mathrm{~h}$. Housework and lawn work is also included. The total score was computed by multiplying the amount of time spent in each activity (hours/week) or participation (yes/ no) in an activity by the empirically derived item weights and summing over all activities.

Daily calcium intake was recorded using a validated questionnaire and was combined with the intake from food with any supplements [28].

\section{Vertebral fracture assessment}

Identification of VF from lateral images of the spine, performed by DXA (Discovery A, Hologic, Waltham, MA, USA), with the participant in supine position, was done by using the software program Physician's Viewer (Hologic). To enhance the ability to visualize each vertebra this software provides tools with which you can adjust the greyscale, alter the magnification, brightness and contrast. The fourth lumbar vertebra was marked by the DXA operator. To visualize the shape of each vertebral body, six markers were placed on the vertebras T4-L4 [29]. One orthopedic surgeon (LJ) analyzed all the 1027 subjects. The fractures were then classified, according to the semi quantitative classification by Genant, as mild, moderate or severe (height reduction $20-25 \%,>25$ $40 \%$ and $>40 \%$, respectively) [30]. The type of fracture, wedge, biconcave or crush was also noted. With the presence of scoliosis, there is a risk that a rotated vertebra can be misinterpreted as a biconcave fracture. To assess the presence of scoliosis the lumbar anteroposterior spine image and whole body image were used. Differential diagnosis of other morphologic deformities of vertebral bodies included short vertebral height, Scheuermann's disease, degenerative scoliosis, Schmorl's nodes and Cupid's bow deformity [31]. When the reproducibility was tested on 50 women (T4-L4), the intraobserver agreement, for vertebras T4-L4, was $98.9 \%$ (kappa score 0.85) and the interobserver agreement was 97.6\% (kappa score 0.72). When mild VFs were excluded the intraobserver agreement was $100 \%$ (kappa score 1.0) and the interobserver agreement 99.6\% (kappascore 0.95).

\section{Statistical analyses}

Independent $t$ tests (for continuous variables) and $\chi^{2}$ (for categorical variables) were used when comparing means or proportions between the groups with and without VFs. After dividing the fracture group into number and severity of fractures, one way analysis of variance (ANOVA) followed by least significant difference (LSD) post hoc test, was used to compare means between groups. The results are presented as mean value \pm standard deviation. Linear regression models were used, with PCS, MCS and physical function tests as dependent variables, and VF and covariates as independent variables, to investigate the associations between $\mathrm{VF}$ and health-related quality of life and physical function with covariates. In these analyses, covariates were age, weight, height, fall accident last year, Parkinson's disease, rheumatoid arthritis, stroke, hypothyroidism, hypertension, cataract, cancer, asthma/bronchitis/emphysema, diabetes, smoking, alcohol, scoliosis and self-reported fracture. PASE was added as covariate and self-reported fracture removed when analyzing physical function tests.

Logistic regression models were used, with back pain as dependent variable and VF and covariates as independent variables, to investigate the associations between VF and back pain with covariates (age, weight, height, fall accident last year, Parkinson's disease, rheumatoid arthritis, stroke, hypothyroidism, cataract, cancer, smoking, alcohol, scoliosis and self-reported fracture). The results are presented as standardized $\beta$ coefficient and $p$ value and odds ratios (OR) with 95\% confidence interval $(\mathrm{CI})$ per standard deviation change in each variable. $P$ values less than 0.05 were considered significant. 
All statistical analyses were performed with SPSS Statistics Version 21 (IBM Corporation, Armonk, NY, USA).

\section{Results}

\section{Characteristics of the cohort}

Characteristics of the cohort divided into having no VF (control group) or increasing numbers of VFs is presented in Table 1. Height at the time for this investigation (but not regarding reported height at the age of 25), self-reported fracture after 50 years of age, usage of osteoporosis medication and glucocorticoids, stroke and self-reported osteoporosis prevalence differed between groups $(p<0.05)$.

\section{Prevalence of fractures}

In this cohort of 1027 women, the prevalence of having at least one VF was $27 \%$ (750 subjects had no VF, 277 had one VF or more). The subjects with VF were divided into having only one VF ( $n=194)$, two VFs $(n=56)$ or more than two VFs $(n=27)$. The subjects having mild, moderate or severe VF were 107, 107 and 63, respectively. The frequency and different types of VFs are described in Fig. 1. There were 406 prevalent $\mathrm{VF}$, of which the most common type was wedge $(n=213,52.5 \%)$ followed by biconcave $(n=183,45.1 \%)$ and crush $(n=10,2.5 \%)$ fracture. When VFs were divided into severity, mild VF was the most common $(n=167,41.1 \%)$ followed by moderate $(n=156,38.4 \%)$ and severe $(n=83$, $20.4 \%)$.

\section{Vertebral fractures and associations to health-related quality of life and back pain}

The physical health was significantly worse and back pain more common in women with any VF than in controls $(43.5 \pm 11.3$ vs. $46.2 \pm 10.5, p<0.001$ and 69.0 vs. $59.9 \%$, $p=0.008$, respectively). The prevalence of back pain increased with both severity of VF and numbers of prevalent VFs. The proportion of women who reported back pain was 84.1 and $77.8 \%$ with prevalent severe VF and more than two VFs, respectively (Tables 2 and 3). PCS12 was the lowest for women with more than two VFs $(39.0 \pm 13.9)$ and for women with severe VF (40.2 \pm 12.6$)$. Also, women with mild VFs had worse physical health (Table 3). In contrast, mental health was not significantly different between the number or severity of VFs compared to controls (Tables 2 and 3).

The association between VF prevalence with PCS and MCS with covariates was investigated using linear regression models (Table 4). In these models, all three groups of VFs (any, number, and severity) were independently associated with physical health $(\beta=-0.079, p=0.007$, and $\beta=-$
$0.083, p=0.005$, and $\beta=-0.091, p=0.002$, respectively). Mental health was not independently associated with VF regardless of VF number or severity (Table 4).

To investigate the association between back pain and VFs, independently of covariates, logistic regression models were used. All three groups of VFs (any, number, and severity) were independently associated with back pain (Odds Ratio (OR) 1.44 [1.06-1.95], OR 1.29 [1.06-1.58] and OR 1.27 [1.09-1.48], respectively) (Table 5).

\section{Vertebral fractures and associations to physical function}

Physical function tests OLS, TUG, TUG manual, walking speed and $30 \mathrm{~s}$ chair stand test were significantly inferior in women with VF compared to controls, while grip strength was not different (Table 2). A similar pattern was seen when severity of VF was compared to controls (Table 3). When comparing frequency of VF to controls, OLS and grip strength were not significantly different than in women without VFs (Table 2). Linear regression models were used to investigate the associations between physical function and VF with covariates (Table 4). In these analyses, increasing number and severity of VFs were independently associated with longer TUG and reduced walking speed (Table 4). The number of VFs was independently associated to TUG manual. Having any VF was independently associated to a worse outcome in the $30 \mathrm{~s}$ chair stand test. OLS and grip strength was not independently associated with VF (Table 4).

The associations between VF and physical health and physical function were also adjusted for back pain in the linear regression model. All significant associations between PCS and physical function measures and VF prevalence in Table 4 remained significant $(p<0.05)$ also after additional adjustment for back pain (data not shown).

\section{Vertebral fractures at the thoracolumbar junction}

We divided the cohort into women with any VF in the thoracolumbar junction (Th12-L1; $n=105)$, women with any VF in other vertebra $(n=172)$ and women without VF $(n=750)$. Using ANOVA with LSD post hoc test, women with any VF at the thoracolumbar junction had lower PCS $(41.5 \pm 11.9,44.8 \pm 10.8,46.2 \pm 10.5$, ANOVA $p<0.001)$, reduced physical function (TUG 9.6 $\pm 3.0,8.8 \pm 3.4,8.5 \pm 2.6 \mathrm{~s}$, $p=0.001$; walking speed $1.18 \pm 0.26,1.26 \pm 0.25,1.29 \pm$ $0.23 \mathrm{~m} / \mathrm{s}, p=<0.001$ ) than women with any VF at other levels and women without VF, respectively. History of back pain was more common in women with VF in the thoracolumbar junction $(n=80,76.2 \%)$ than in women with VF in other vertebras $(n=111,64.5 \%)$ and in women without VFs (449 $(59.9 \%)$, respectively $(p=0.004))$. 
Table 1 Characteristics of older women without VFA-diagnosed vertebral fracture (VF) and increasing number of vertebral fractures

\begin{tabular}{|c|c|c|c|c|c|}
\hline & No VF & One VF & Two VFs & More than two VFs & $p$ value $\mathrm{e}^{\mathrm{s}, \mathrm{t}}$ \\
\hline & $N=750$ & $N=194$ & $N=56$ & $N=27$ & \\
\hline Age, years & $77.7 \pm 1.6$ & $77.8 \pm 1.4$ & $77.8 \pm 1.4$ & $77.9 \pm 1.4$ & 0.690 \\
\hline Height $(\mathrm{cm})$ & $162.4 \pm 5.9$ & $161.4 \pm 5.3^{\S}$ & $161.6 \pm 6.1$ & $159.8 \pm 4.9^{*}$ & 0.014 \\
\hline Height at age $25(\mathrm{~cm})$ & $165.6 \pm 5.6^{\mathrm{i}}$ & $165.5 \pm 4.9$ & $165.2 \pm 5.6$ & $166.3 \pm 4.8$ & 0.872 \\
\hline Weight (kg) & $68.5 \pm 11.8$ & $67.8 \pm 10.9$ & $71.2 \pm 14.5$ & $66.3 \pm 11.0$ & 0.193 \\
\hline Body mass index $\left(\mathrm{kg} / \mathrm{m}^{2}\right)$ & $26.0 \pm 4.3$ & $26.0 \pm 3.8$ & $27.3 \pm 5.1$ & $25.9 \pm 3.9$ & 0.187 \\
\hline Physical activity (PASE) & $110.3 \pm 53.7^{\mathrm{j}}$ & $101.7 \pm 45.1^{\circ}$ & $110.9 \pm 53.4^{\mathrm{q}}$ & $100.5 \pm 69.3$ & 0.181 \\
\hline Fall accident last year, \% (n) & $29.7(223)$ & $33.0(64)$ & $39.3(22)$ & $37.0(10)$ & 0.366 \\
\hline Calcium intake (mg/day) & $695.5 \pm 386.1^{\mathrm{k}}$ & $707.2 \pm 414.4$ & $708.4 \pm 389.3$ & $897.9 \pm 434.0$ & 0.075 \\
\hline Self-reported fracture, $\%(n)^{\mathrm{a}}$ & $34.7(259)^{\mathrm{k}}$ & $39.4(76)^{\mathrm{o}}$ & $60.7(34)$ & $66.7(18)$ & $<0.001$ \\
\hline Smoking, \% $(n)^{\mathrm{b}}$ & $6.6(50)$ & $6.2(12)$ & $3.6(2)$ & $7.4(2)$ & 0.827 \\
\hline Alcohol, \% $(n)^{\mathrm{c}}$ & $0.1(1)^{1}$ & $0.0(0)$ & $0.0(0)$ & $0.0(0)$ & 0.946 \\
\hline \multicolumn{6}{|l|}{ Pharmacological treatment } \\
\hline Glucocorticoids, previous use, $\%(n)^{\mathrm{d}}$ & $2.3(17)^{\mathrm{m}}$ & $2.1(4)^{\mathrm{p}}$ & $7.3(4)^{\mathrm{q}}$ & $7.7(2)^{\mathrm{r}}$ & 0.060 \\
\hline $\begin{array}{l}\text { Glucocorticoids, current } \\
\text { use } \%(n)^{\mathrm{e}}\end{array}$ & $2.4(18)$ & $3.1(6)$ & $5.4(3)$ & $11.1(3)$ & 0.040 \\
\hline Osteoporosis medication, previous use $\%(n)^{\mathrm{f}}$ & $13.1(98)$ & $19.6(38)$ & $29.1(16)^{\mathrm{q}}$ & $63.0(17)$ & $<0.001$ \\
\hline Osteoporosis medication, current use $\%(n)^{g}$ & $0.1(36)$ & $5.2(10)$ & $17.9(10)$ & $22.2(6)$ & $<0.001$ \\
\hline \multicolumn{6}{|l|}{ Medical history } \\
\hline Parkinson's disease, \% (n) & $0.5(4)$ & $0.5(1)$ & $0.0(0)$ & $3.7(1)$ & 0.179 \\
\hline Rheumatoid Arthritis, \% (n) & $3.3(25)^{\mathrm{n}}$ & $4.6(9)$ & $1.8(1)$ & $0.0(0)$ & 0.513 \\
\hline Stroke, $\%(n)$ & $8.3(62)$ & $7.2(14)$ & $3.6(2)$ & $25.9(7)$ & 0.005 \\
\hline Hypothyroidism, \% (n) & $13.3(99)^{\mathrm{k}}$ & $10.9(21)^{\mathrm{o}}$ & $19.6(11)$ & $11.1(3)$ & 0.384 \\
\hline Osteoporosis, $\%(n)^{\mathrm{h}}$ & $14.4(108)^{1}$ & $23.2(45)$ & $32.1(18)$ & $70.4(19)$ & $<0.001$ \\
\hline Hypertension, \% (n) & $50.4(378)$ & $53.6(104)$ & $70.4(27)$ & 70.4 (19) & 0.187 \\
\hline Cataract, \% (n) & $42.5(319)$ & $47.4(92)$ & $53.6(30)$ & $48.1(13)$ & 0.281 \\
\hline Cancer, $\%(n)$ & $19.3(145)$ & $17.5(34)$ & $12.5(7)$ & $25.9(7)$ & 0.440 \\
\hline
\end{tabular}

Values are presented as mean \pm standard deviation for continuous variables and as percentage and number for categorical variables

PASE Physical Activity Scale for the Elderly

${ }^{a}$ After 50 years of age, fracture of hip, vertebra, lower arm/wrist, clavicula/shoulder, proximal humerus, costae, femur, knee, lower leg, ancle/foot/toe, hand/finger

${ }^{\mathrm{b}}$ Smoking at any time during the last 6 months

c 21 or more units per week (as for FRAX)

${ }^{\mathrm{d}}$ At least 3 months of their life

${ }^{\mathrm{e}}$ Usage based on the last 30 days

${ }^{\mathrm{f}}$ Any usage of bisphosphonate, zoledronic acid, strontiumranelat, parathyroid hormone, denosumab

${ }^{\mathrm{g}}$ Bisphosphonates and denosumab last month

${ }^{\mathrm{h}}$ Self-reported from the question "Have the doctor told you that you have osteoporosis?"

i 688

j 747

k 746

1749

$\mathrm{m} 726$

n 748

${ }^{\circ} 193$

$\mathrm{p}_{188}$

${ }^{\mathrm{q}} 55$

${ }^{\mathrm{r}} 26$

${ }^{\mathrm{s}}$ Continuous variables one way ANOVA followed by least significant difference post hoc test

${ }^{\mathrm{t}}$ Categorical variables $\chi^{2}$ test, Pearson's chi-square. Significance was defined by a $p$ value $<0.05$ and significant values are presented in bold

$\S$ One VF vs. no VF

*More than two VFs vs. no VF 
Fig. 1 The number of vertebral fractures presented according to different types of fractures and vertebral level (T4-L4)

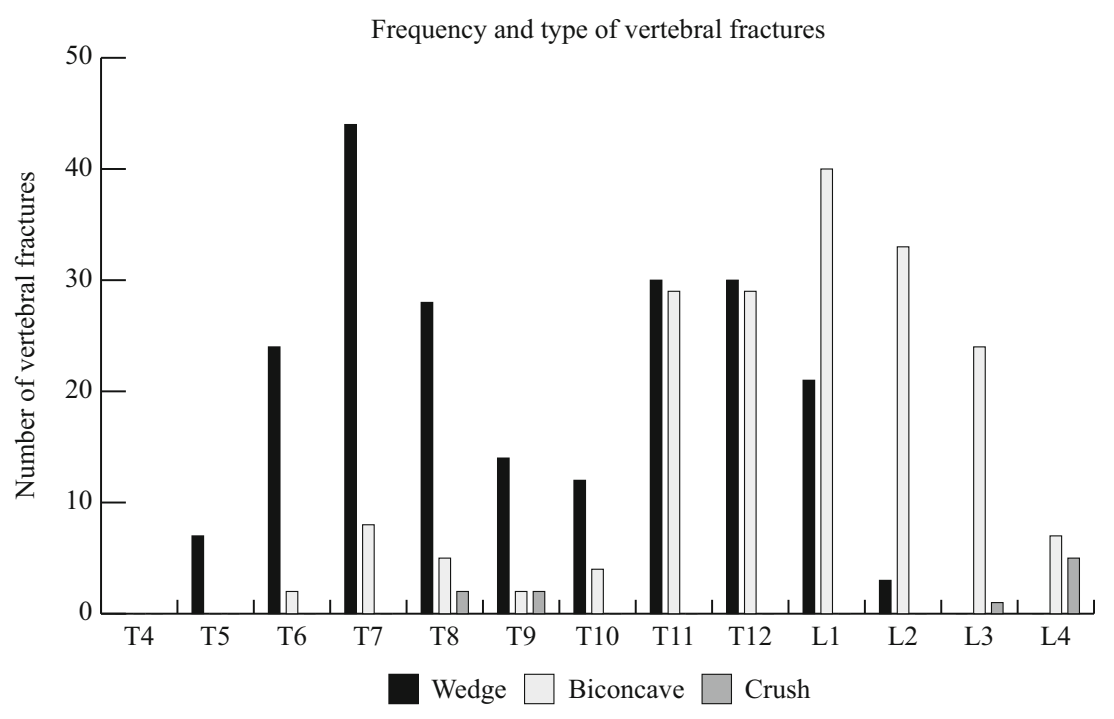

\section{Discussion}

In this population-based cross-sectional study of ambulant older women, we found that prevalent VFA diagnosed VF number and severity were independently associated to physical health (PCS SF-12), back pain and physical function (TUG, walking speed and 30 -s chair stand test). Interestingly, also mild VFs were associated with reduced physical function and physical health, indicating that these fractures are also clinically relevant to diagnose. To our knowledge this is the first study investigating associations between physical function, assessed by multiple, validated performance-based measures, and prevalent VF identified using VFA.

Hall et al. investigated the quality of life and functional impairment in 100 women with VF, diagnosed using spine radiographs, and 100 matched controls from the community. In this case-control study the women with VF had worse physical function compared to controls assessed by $3 \mathrm{~m}$ TUG $(13.8 \pm 7.3 \mathrm{~s}$ vs. $10.1 \pm 4.1, p=<0.01)$ [32]. In a cohort study of community-dwelling women, aged 60 years and over with VFs, Morris et al. investigated if balance tests could predict falls [33]. Several indices, including the $5 \mathrm{~m}$-TUG test, timed 10-m walk and the TURN180 test, reflecting poor balance, were associated with falls. After multivariable analyses, they found that the best test to predict falls in older women with VF was the TUG test. In the present study, TUG was independently associated with VF. This data supports the concept that TUG could be a useful tool in the clinical setting to measure physical mobility and balance in women with VF, in order to choose appropriate interventions to reduce falls. Further studies are needed to validate cut-off points for TUG in women with VF.

Lower grip strength in men and women with VF than in controls has been reported from the MrOS and MsOS study from Hongkong performed by Kwok et al. [34]. After adjustments with covariates, a lower grip strength remained associated to prevalent VF among men but not among women. In the present study, we did not find any associations between VF and grip strength.

In the case-control study by Hall et al., the physical and mental component summary indexes of the SF-36 were lower in the VF group than in controls, and the PCS differed more than the MCS (PCS $36 \pm 11$ vs. $48 \pm 9, p=<0.001$, MCS $50 \pm$ 11 vs. $54 \pm 8, p=<0.05$, respectively) [32]. In our cohort, we also found a lower PCS (SF-12) in the VF group compared to controls, while the mental health did not show any significant difference between groups (Table 2). The association between VF, assessed by conventional spine radiographs, and SF-12 was previously investigated among 804 women. Mild and moderate/severe VFs were associated with inferior scores in SF-12 PCS (non-adjusted analysis) but not in MCS. In multivariable regression analyses lower PCS scores were associated to prevalent VF [35]. These findings are in concordance with our results, which revealed independent significant associations between PCS, not only to severity of VF, but also to number of VF (Table 4). Similar results were seen in the Tromsø Study, in which quality of life was measured using EQ-5D-3 L [18]. In women, after adjustments, EQ-5D-3 L and back pain were associated with prevalent number and severity of VF, verified by VFA.

Our secondary aim was to investigate the clinical importance of identifying mild fractures. When interpreting the relevance of mild VF it is of importance to take into account that non-fracture deformities due to degenerative disease, a condition common in older people, can be misinterpreted as a VF. Awareness of identification of typical signs of osteoarthritis as osteophytes, narrow disc spaces and lower anterior height is necessary. One way to distinguish wedge deformation due to osteoporosis, from osteoarthritis, is that not only the anterior/ 
Table 2 Health-related quality of life, back pain and physical function in relation to number of vertebral fractures (VF)

\begin{tabular}{|c|c|c|c|c|c|c|c|}
\hline & $\begin{array}{l}\text { No VF } \\
N=750\end{array}$ & $\begin{array}{l}\text { VF (any) } \\
N=277\end{array}$ & $p$ value $^{\mathrm{a}}$ & $\begin{array}{l}\text { One VF } \\
N=194\end{array}$ & $\begin{array}{l}\text { Two VF } \\
N=56\end{array}$ & $\begin{array}{l}\text { More than two VFs } \\
N=27\end{array}$ & $\begin{array}{l}\text { ANOVA }^{\mathrm{A}} \\
p \text { value }\end{array}$ \\
\hline \multicolumn{8}{|l|}{ SF-12 } \\
\hline $\mathrm{PCS} 12$ & $46.2 \pm 10.5^{\mathrm{c}}$ & $43.5 \pm 11.3^{\mathrm{j}}$ & $<0.001$ & $43.7 \pm 11.1^{\S o}$ & $45.0 \pm 10.6$ & $39.0 \pm 13.9^{* \wedge \# \mathrm{w}}$ & $<0.001$ \\
\hline MCS12 & $54.3 \pm 8.5^{\mathrm{c}}$ & $54.7 \pm 9.1^{\mathrm{j}}$ & 0.543 & $54.5 \pm 8.9^{\circ}$ & $55.4 \pm 9.4$ & $54.1 \pm 9.7^{\mathrm{w}}$ & 0.810 \\
\hline Back pain, \% (n) & $59.9(449)$ & $69.0(191)$ & $0.008^{b}$ & $67.5(131)$ & $69.6(39)$ & $77.8(21)$ & $0.042^{\mathrm{b}}$ \\
\hline \multicolumn{8}{|l|}{ Function } \\
\hline OLS (s) & $15.3 \pm 10.4^{\mathrm{d}}$ & $13.5 \pm 10.3^{\mathrm{k}}$ & 0.030 & $13.0 \pm 10.1^{\mathrm{p}}$ & $15.9 \pm 11.1^{\mathrm{t}}$ & $11.8 \pm 9.2^{\times}$ & 0.051 \\
\hline TUG (s) & $8.5 \pm 2.6^{\mathrm{e}}$ & $9.1 \pm 3.2^{\mathrm{j}}$ & 0.004 & $9.1 \pm 3.4^{\S 0}$ & $8.4 \pm 2.2$ & $10.3 \pm 3.6^{*^{\wedge} \# \mathrm{w}}$ & $<0.001$ \\
\hline TUG manual (s) & $10.1 \pm 2.6^{\mathrm{f}}$ & $10.5 \pm 2.8^{1}$ & 0.027 & $10.5 \pm 2.7^{\mathrm{q}}$ & $10.0 \pm 2.3$ & $12.2 \pm 3.8^{* \Uparrow \# y}$ & 0.001 \\
\hline Walking speed, (m/s) & $1.29 \pm 0.23^{\mathrm{g}}$ & $1.23 \pm 0.26^{\mathrm{j}}$ & 0.001 & $1.23 \pm 0.25^{\circ}$ & $1.29 \pm 0.24$ & $1.10 \pm 0.28^{* \wedge \# \mathrm{w}}$ & $<0.001$ \\
\hline 30 -s chair stand test, $(n)$ & $11.4 \pm 3.4^{\mathrm{h}}$ & $10.7 \pm 3.1^{\mathrm{m}}$ & 0.006 & $10.6 \pm 3.1^{\S \mathrm{r}}$ & $11.2 \pm 3.1^{\mathrm{u}}$ & $10.5 \pm 3.6^{\mathrm{z}}$ & 0.028 \\
\hline Grip strength (kg) & $13.4 \pm 5.2^{\mathrm{i}}$ & $13.1 \pm 5.8^{\mathrm{n}}$ & 0.358 & $13.0 \pm 5.6^{\mathrm{s}}$ & $13.8 \pm 6.1^{\mathrm{v}}$ & $12.1 \pm 6.2^{\mathrm{w}}$ & 0.481 \\
\hline
\end{tabular}

Results are presented as mean \pm standard deviation for continuous variables and as percentage and number for categorical variables

PCS Physical Component Summary, MCS Mental Component Summary, OLS one-leg standing, TUG Timed Up and Go, TUG manual Timed Up and Go with a glass of water in one hand. Maximum grip strength is presented for the dominant hand

${ }^{\text {A }}$ One way ANOVA, followed by least significant difference post hoc test

${ }^{\mathrm{a}}$ Independent samples $t$ test

${ }^{\mathrm{b}} \chi^{2}$ test

c 749

d 613

e 747

f 735

g 745

h 710 ,

i 729

j 275

${ }^{\mathrm{k}} 213$

${ }^{1} 267$

$\mathrm{m}_{256}$

${ }^{\mathrm{n}} 270$

${ }^{\circ} 193$

p 155

${ }^{\mathrm{q}} 188$

${ }^{\mathrm{r}} 182$

s 189

${ }^{\mathrm{t}} 41$

u 53

v 55

${ }^{\mathrm{w}} 26$

$\mathrm{x} 17$

${ }^{\mathrm{y}} 23$

$\mathrm{z}_{21}$

$\S$ One VF vs. no VF

*More than two VFs vs. no VF

${ }^{\wedge}$ More than two VFs vs. one VF

\# More than two VFs vs. two VFs. Significance was defined by a $p$ value $<0.05$ and significant values are presented in bold 
Table 3 Health-related quality of life, back pain and physical function in relation to severity of $\mathrm{VF}$

\begin{tabular}{|c|c|c|c|c|c|}
\hline & $\begin{array}{l}\text { No VF } \\
N=750\end{array}$ & $\begin{array}{l}\text { Mild VF } \\
N=107\end{array}$ & $\begin{array}{l}\text { Moderate VF } \\
N=107\end{array}$ & $\begin{array}{l}\text { Severe VF } \\
N=63\end{array}$ & $\begin{array}{l}\text { ANOVA }^{\mathrm{A}} \\
p \text { value }\end{array}$ \\
\hline \multicolumn{6}{|l|}{ SF-12 } \\
\hline $\mathrm{PCS} 12$ & $46.2 \pm 10.5^{\mathrm{a}}$ & $43.8 \pm 10.9^{\S}$ & $45.3 \pm 10.6^{\mathrm{k}}$ & $40.2 \pm 12.6^{*^{\wedge} \#}$ & $<0.001$ \\
\hline MCS12 & $54.3 \pm 8.5^{\mathrm{a}}$ & $54.2 \pm 8.3^{\mathrm{h}}$ & $55.1 \pm 9.3^{\mathrm{k}}$ & $54.7 \pm 10.1$ & 0.832 \\
\hline Back pain, $\%(n)$ & 59.9 (449) & $65.4(70)$ & $63.6(68)$ & $84.1(53)$ & $\mathbf{0 . 0 0 2}^{\mathrm{B}}$ \\
\hline \multicolumn{6}{|l|}{ Function } \\
\hline OLS (s) & $15.3 \pm 10.4^{\mathrm{b}}$ & $12.7 \pm 9.9^{\S \mathrm{h}}$ & $15.2 \pm 10.5^{1}$ & $11.8 \pm 10.4^{* \mathrm{o}}$ & 0.038 \\
\hline TUG (s) & $8.5 \pm 2.6^{\mathrm{c}}$ & $8.5 \pm 2.2$ & $8.8 \pm 2.4^{\mathrm{i}}$ & $10.5 \pm 5.0^{* \wedge \# p}$ & $<0.001$ \\
\hline TUG manual (s) & $10.1 \pm 2.6^{\mathrm{d}}$ & $10.5 \pm 2.8^{\mathrm{i}}$ & $10.2 \pm 2.6^{\mathrm{m}}$ & $11.1 \pm 3.0 * \# \mathrm{q}$ & 0.027 \\
\hline Walking speed, (m/s) & $1.29 \pm 0.23^{\mathrm{e}}$ & $1.25 \pm 0.22$ & $1.26 \pm 0.25^{\mathrm{i}}$ & $1.13 \pm 0.30 *^{* \# p}$ & $<0.001$ \\
\hline 30 -s chair stand test $(n)$ & $11.4 \pm 3.4^{\mathrm{f}}$ & $10.7 \pm 3.2^{\S j}$ & $11.0 \pm 3.1^{\mathrm{n}}$ & $10.2 \pm 2.9^{* \mathrm{r}}$ & 0.021 \\
\hline Grip strength, (kg) & $13.4 \pm 5.2^{\mathrm{g}}$ & $13.1 \pm 6.0^{\mathrm{k}}$ & $13.6 \pm 5.5^{\mathrm{i}}$ & $12.0 \pm 5.8^{\mathrm{s}}$ & 0.216 \\
\hline
\end{tabular}

Results are presented as mean \pm standard deviation for continuous variables and as percentage and number for categorical variables

PCS Physical Component Summary, MCS Mental Component Summary, OLS one-leg standing, TUG Timed Up and Go, TUG manual Timed Up and Go with a glass of water in one hand. Maximum grip strength is presented for the dominant hand

${ }^{\mathrm{A}}$ One way ANOVA, followed by least significant difference post hoc test

${ }^{\text {B }} \chi^{2}$ test was used. Significance was defined by a $p$ value $<0.05$ and significant values are presented in bold

${ }^{\mathrm{a}} 749$

${ }^{\mathrm{b}} 613$

${ }^{\mathrm{c}} 747$

d 735

e 745

f 710

g 729

h 90

${ }^{\mathrm{i}} 106$

j 102

${ }^{\mathrm{k}} 105$

${ }^{1} 79$

${ }^{\mathrm{m}} 104$

${ }^{\mathrm{n}} 101$

${ }^{\circ} 44$

p 62

q 57

${ }^{\mathrm{r}} 53$

${ }^{\mathrm{s}} 59$

${ }^{\S}$ Mild VF vs. no VF

*Severe VF vs. no VF

^Severe VF vs. mild VF

${ }^{\text {\# }}$ Severe VF vs. moderate VF posterior height ratio is lower but also the mid/posterior vertebral height ratio [36]. The latter was also considered in this study. By using Genant semi-quantitative classification, in which a mild fracture is defined by a height reduction of 20 $25 \%$, we have taken into consideration the well accepted cutoff of $20 \%$ height reduction to avoid inclusion of non-fracture deformities [31]. The importance of diagnosing mild fractures can be explained by the vertebral fracture cascade. With the presence of a VF (all grades of severity) comes changes in spinal biomechanics, due to disc degeneration and bone loss, with increased loading on adjacent vertebra giving an increased risk of incident VF [37]. Roux et al. followed 2551 
Table 4 Association between health-related quality of life and physical function and vertebral fracture (VF) number and severity in older women

\begin{tabular}{lllllll}
\hline & VF (no/yes) & & Number of VF & \multicolumn{2}{l}{ Severity of VF } \\
\hline & $\beta$ & $p$ value & $\beta$ & $p$ value & $\beta$ & $p$ value \\
SF-12 & & & & & & \\
PCS & -0.079 & $\mathbf{0 . 0 0 7}$ & -0.083 & $\mathbf{0 . 0 0 5}$ & -0.091 & $\mathbf{0 . 0 0 2}$ \\
MCS & 0.012 & $\mathrm{~ns}$ & 0.015 & $\mathrm{~ns}$ & 0.019 & $\mathrm{~ns}$ \\
Function & & & & & & \\
OLS (s) & & & & & & \\
TUG, (s) & -0.042 & $\mathrm{~ns}$ & -0.027 & $\mathrm{~ns}$ & -0.034 & $\mathrm{~ns}$ \\
TUG manual (s) & 0.067 & $\mathbf{0 . 0 2 1}$ & 0.067 & $\mathbf{0 . 0 2 0}$ & 0.109 & $<\mathbf{0 . 0 0 1}$ \\
Walking speed, $(\mathrm{m} / \mathrm{s})$ & 0.041 & $\mathrm{~ns}$ & 0.059 & $\mathbf{0 . 0 4 3}$ & 0.043 & $\mathrm{~ns}$ \\
30-s chair stand test $(n)$ & -0.071 & $\mathbf{0 . 0 0 9}$ & -0.078 & $\mathbf{0 . 0 0 4}$ & -0.096 & $<\mathbf{0 . 0 0 1}$ \\
Grip strength $(\mathrm{kg})$ & -0.075 & $\mathbf{0 . 0 1 2}$ & -0.057 & $\mathrm{~ns}$ & -0.075 & $\mathbf{0 . 0 1 3}$ \\
\hline
\end{tabular}

Linear regression models were used to investigate associations between HRQL and physical function, as dependent variables, and VF and covariates (age, weight, height, fall accident last year, Parkinson's disease, rheumatoid arthritis, stroke, hypothyroidism, hypertension, cataract, cancer, asthma/bronchitis/emphysema, diabetes, smoking, alcohol, scoliosis, self-reported fracture), as independent variables. The results are presented as standardized $\beta$ coefficients (SD change in the dependant variable per SD change in the independent variable) and $p$ values. Significance was defined by a $p$ value $<0.05$ and significant values are presented in bold

PCS Physical Component Summary, MCS Mental Component Summary, OLS one-leg standing, TUG Timed Up and Go, TUG manual Timed Up and Go with a glass of water in one hand. Maximum grip strength is presented for the dominant hand

${ }^{\text {a }}$ PASE included as covariate and self-reported fracture not included postmenopausal women with osteoporosis for 4 years. VFs were diagnosed by spine radiographs. They found that mild $\mathrm{VF}$ was a risk factor for subsequent VF during a 4-year period (RR 1.8, $p=<0.001$ ) [38]. Although this vertebral fracture cascade is a known phenomenon, most studies investigating VFs and their associations with physical health and function have focused on grade 2 and 3 VFs [39]. The prevalence of mild VF in our material (41.1\%) was similar to the prevalence of minor vertebral deformities found by Kanterewicz et al. (39.3\%), using McCloskey criteria and Lunar DXA equipment [17]. We found that mild VFs were associated not only

Table 5 Association between back pain and vertebral fracture (VF) number and severity in older women

\begin{tabular}{llll}
\hline & VF (no/yes) & Number of VF & Severity of VF \\
\hline OR (95\% CI) & OR $(95 \%$ CI $)$ & OR (95\% CI) \\
$\begin{array}{l}\text { Back pain, } \\
\text { yes/no }\end{array}$ & $\mathbf{1 . 4 4}(\mathbf{1 . 0 6}$ to $\mathbf{1 . 9 5})$ & $\mathbf{1 . 2 9}(\mathbf{1 . 0 6}$ to $\mathbf{1 . 5 8})$ & $\mathbf{1 . 2 7}(\mathbf{1 . 0 9}$ to 1.48) \\
\hline
\end{tabular}

Logistic regression models were used to investigate associations between back pain, as dependent variable, and VF and covariates (age, weight, height, fall accident last year, Parkinson's disease, rheumatoid arthritis, stroke, hypothyroidism, cataract, cancer, smoking, alcohol, self-reported fracture, scoliosis), as independent variables. The results are presented as OR with 95\% CI per SD decrease

Significance was defined by a $p$ value $<0.05$ and significant values are presented in bold

${ }^{\text {a }}$ Self-reported from the question "Have you had back pain the past 12 months? with reduced physical health (SF-12), but also with inferior physical function. In recent studies, VFA has been described as a valuable method to detect grades 2 and 3 VFs [14-16]. We hypothesize that VFA should be considered a valuable method also for diagnosing mild VF, since these fractures most likely contribute to the vertebral fracture cascade and are associated with physical health and function.

A limitation in this study is that a causal relationship cannot be assured with this cross-sectional design. Another limitation is that the VFA identified VF were not validated against spine radiography in this cohort. When interpreting results from generic health status questionnaires, an identified statistically significant difference does not always constitute a clinically relevant difference. The minimal clinically important difference (MCID) of SF-12 in patients with subacute and chronic low back pain was reported to be 3.3 or greater, in PCS [40]. In this study, the difference in PCS between women with and without any VF was 2.7, indicating that this difference was just below being clinically important. However, when comparing PCS in women without VF and women having more than two VFs, the difference in PCS was 7.2, which is more than twice the MCID. To our knowledge there are to date no studies concerning MCID for PCS in people with VF.

One of the strengths in this study is that all the VFA analyses were performed by one operator. Another strength is that the cohort is the so far largest to investigate VF, identified using VFA, and the relation to physical function, assessed by multiple performance-based measures. The populationbased design in this study, compared to case-control studies, 
reduces the risk of confounding bias from recent prior fracture and large differences in anthropometrics and morbidity.

In conclusion, in this cross-sectional population-based study of older women, we found that prevalent VF, diagnosed by VFA, was associated with worse physical health, increased prevalence of back pain and reduced physical function. These findings support the use of VFA in order to identify frailty due to VF of all severity.

Acknowledgments This study was funded by the Swedish Research Council (VR), the ALF/LUA grant from the Sahlgrenska University Hospital, King Gustaf V's and Queen Victoria's Freemason Foundation and the Inga-Britt and Arne Lundberg Foundation.

\section{Compliance with ethical standards}

Conflict of interest Mattias Lorentzon has received lecture fees from Amgen, Lilly, Meda, UCB, Renapharma and consulting fees from Radius Health, and Consilient Health. All other authors state that they have no conflict of interests.

Open Access This article is distributed under the terms of the Creative Commons Attribution-NonCommercial 4.0 International License (http:// creativecommons.org/licenses/by-nc/4.0/), which permits any noncommercial use, distribution, and reproduction in any medium, provided you give appropriate credit to the original author(s) and the source, provide a link to the Creative Commons license, and indicate if changes were made.

\section{References}

1. Chrischilles EA, Butler CD, Davis CS, Wallace RB (1991) A model of lifetime osteoporosis impact. Arch Intern Med 151(10):20262032

2. Cooper C, Atkinson EJ, O'Fallon WM, Melton LJ 3rd (1992) Incidence of clinically diagnosed vertebral fractures: a populationbased study in Rochester, Minnesota, 1985-1989. J Bone Miner Res 7(2):221-227. https://doi.org/10.1002/jbmr.5650070214

3. Melton LJ 3rd, Lane AW, Cooper C, Eastell R, O'Fallon WM, Riggs BL (1993) Prevalence and incidence of vertebral deformities. Osteoporos Int 3(3):113-119

4. Johnell O, Kanis JA (2006) An estimate of the worldwide prevalence and disability associated with osteoporotic fractures. Osteoporos Int 17(12):1726-1733. https://doi.org/10.1007/ s00198-006-0172-4

5. O'Neill TW, Felsenberg D, Varlow J, Cooper C, Kanis JA, Silman AJ (1996) The prevalence of vertebral deformity in european men and women: the European vertebral osteoporosis study. J Bone Miner Res 11(7):1010-1018. https://doi.org/10.1002/jbmr. 5650110719

6. Fechtenbaum J, Cropet C, Kolta S, Horlait S, Orcel P, Roux C (2005) The severity of vertebral fractures and health-related quality of life in osteoporotic postmenopausal women. Osteoporos Int 16(12):2175-2179. https://doi.org/10.1007/s00198-005-2023-0

7. Hasserius R, Karlsson MK, Nilsson BE, Redlund-Johnell I, Johnell O, European Vertebral Osteoporosis S (2003) Prevalent vertebral deformities predict increased mortality and increased fracture rate in both men and women: a 10-year population-based study of 598 individuals from the Swedish cohort in the European vertebral osteoporosis study. Osteoporos Int 14(1):61-68. https://doi.org/10. 1007/s00198-002-1316-9

8. Nuti R, Caffarelli C, Guglielmi G, Gennari L, Gonnelli S (2014) Undiagnosed vertebral fractures influence quality of life in postmenopausal women with reduced ultrasound parameters. Clin Orthop Relat Res 472(7):2254-2261. https://doi.org/10.1007/ s11999-014-3588-8

9. Al-Sari UA, Tobias J, Clark E (2016) Health-related quality of life in older people with osteoporotic vertebral fractures: a systematic review and meta-analysis. Osteoporos Int 27(10):2891-2900. https://doi.org/10.1007/s00198-016-3648-x

10. Lindsay R, Silverman SL, Cooper C, Hanley DA, Barton I, Broy SB, Licata A, Benhamou L, Geusens P, Flowers K, Stracke H, Seeman E (2001) Risk of new vertebral fracture in the year following a fracture. JAMA 285(3):320-323

11. Melton LJ 3rd, Atkinson EJ, Cooper C, O'Fallon WM, Riggs BL (1999) Vertebral fractures predict subsequent fractures. Osteoporos Int 10(3):214-221

12. Genant HK, Li J, CY W, Shepherd JA (2000) Vertebral fractures in osteoporosis: a new method for clinical assessment. J Clin Densitom 3(3):281-290

13. Rea JA, Li J, Blake GM, Steiger P, Genant HK, Fogelman I (2000) Visual assessment of vertebral deformity by X-ray absorptiometry: a highly predictive method to exclude vertebral deformity. Osteoporos Int 11(8):660-668. https://doi.org/10.1007/ s001980070063

14. Vokes TJ, Dixon LB, Favus MJ (2003) Clinical utility of dualenergy vertebral assessment (DVA). Osteoporos Int 14(11):871878. https://doi.org/10.1007/s00198-003-1461-9

15. Schousboe JT, Debold CR (2006) Reliability and accuracy of vertebral fracture assessment with densitometry compared to radiography in clinical practice. Osteoporos Int 17(2):281-289. https://doi. org/10.1007/s00198-005-2010-5

16. Domiciano DS, Figueiredo CP, Lopes JB, Kuroishi ME, Takayama L, Caparbo VF, Fuller P, Menezes PF, Scazufca M, Bonfa E, Pereira RM (2013) Vertebral fracture assessment by dual X-ray absorptiometry: a valid tool to detect vertebral fractures in communitydwelling older adults in a population-based survey. Arthritis Care Res 65(5):809-815. https://doi.org/10.1002/acr.21905

17. Kanterewicz E, Puigoriol E, Garcia-Barrionuevo J, del Rio L, Casellas M, Peris P, Frodos Research G (2014) Prevalence of vertebral fractures and minor vertebral deformities evaluated by DXAassisted vertebral fracture assessment (VFA) in a population-based study of postmenopausal women: the FRODOS study. Osteoporos Int 25(5):1455-1464. https://doi.org/10.1007/s00198-014-2628-2

18. Waterloo S, Sogaard AJ, Ahmed LA, Damsgard E, Morseth B, Emaus N (2013) Vertebral fractures and self-perceived health in elderly women and men in a population-based cross-sectional study: the Tromsø Study 2007-08. BMC Geriatr 13:102. https:// doi.org/10.1186/1471-2318-13-102

19. Giorgetti MM, Harris BA, Jette A (1998) Reliability of clinical balance outcome measures in the elderly. Physiother Res Int 3(4): 274-283

20. Podsiadlo D, Richardson S (1991) The timed "Up \& Go": a test of basic functional mobility for frail elderly persons. J Am Geriatr Soc 39(2):142-148

21. Jones CJ, Rikli RE, Beam WC (1999) A 30-s chair-stand test as a measure of lower body strength in community-residing older adults. Res Q Exerc Sport 70(2):113-119. https://doi.org/10.1080/ 02701367.1999.10608028

22. Wolf SL, Catlin PA, Gage K, Gurucharri K, Robertson R, Stephen K (1999) Establishing the reliability and validity of measurements of walking time using the Emory Functional Ambulation Profile. Phys Ther 79(12):1122-1133 
23. Bohannon RW, Andrews AW, Thomas MW (1996) Walking speed: reference values and correlates for older adults. J Orthop Sports Phys Ther 24(2):86-90. https://doi.org/10.2519/jospt.1996.24.2.86

24. Peolsson A, Hedlund R, Oberg B (2001) Intra- and inter-tester reliability and reference values for hand strength. J Rehabil Med 33(1):36-41

25. Sundh D, Nilsson AG, Nilsson M, Johansson L, Mellstrom D, Lorentzon M (2017) Increased cortical porosity in women with hip fracture. J Intern Med 281(5):496-506. https://doi.org/10. 1111/joim. 12587

26. Ware J Jr, Kosinski M, Keller SD (1996) A 12-item short-form health survey: construction of scales and preliminary tests of reliability and validity. Med Care 34(3):220-233

27. Washburn RA, Smith KW, Jette AM, Janney CA (1993) The physical activity scale for the elderly (PASE): development and evaluation. J Clin Epidemiol 46(2):153-162

28. Angbratt M, Moller M (1999) Questionnaire about calcium intake: can we trust the answers? Osteoporos Int 9(3):220-225. https://doi. org/10.1007/s001980050140

29. Blake GM, Rea JA, Fogelman I (1997) Vertebral morphometry studies using dual-energy x-ray absorptiometry. Semin Nucl Med 27(3):276-290

30. Genant HK, CY W, van Kuijk C, Nevitt MC (1993) Vertebral fracture assessment using a semiquantitative technique. J Bone Miner Res 8(9):1137-1148. https://doi.org/10.1002/jbmr.5650080915

31. Griffith JF (2015) Identifying osteoporotic vertebral fracture. Quant Imaging Med Surg 5(4):592-602. https://doi.org/10.3978/j.issn. 2223-4292.2015.08.01

32. Hall SE, Criddle RA, Comito TL, Prince RL (1999) A case-control study of quality of life and functional impairment in women with long-standing vertebral osteoporotic fracture. Osteoporos Int 9(6): 508-515. https://doi.org/10.1007/s001980050178

33. Morris R, Harwood RH, Baker R, Sahota O, Armstrong S, Masud T (2007) A comparison of different balance tests in the prediction of falls in older women with vertebral fractures: a cohort study. Age Ageing 36(1):78-83. https://doi.org/10.1093/ageing/afl147

34. Kwok AW, Gong JS, Wang YX, Leung JC, Kwok T, Griffith JF, Leung PC (2013) Prevalence and risk factors of radiographic vertebral fractures in elderly Chinese men and women: results of Mr. OS (Hong Kong) and Ms. OS (Hong Kong) studies. Osteoporos Int 24(3):877-885. https://doi.org/10.1007/s00198-012-2040-8

35. Sanfelix-Genoves J, Hurtado I, Sanfelix-Gimeno G, Reig-Molla B, Peiro S (2011) Impact of osteoporosis and vertebral fractures on quality-of-life. A population-based study in Valencia, Spain (The FRAVO Study). Health Qual Life Outcomes 9:20. https://doi.org/ 10.1186/1477-7525-9-20

36. Abdel-Hamid Osman A, Bassiouni H, Koutri R, Nijs J, Geusens P, Dequeker J (1994) Aging of the thoracic spine: distinction between wedging in osteoarthritis and fracture in osteoporosis - a crosssectional and longitudinal study. Bone 15(4):437-442

37. Broy SB (2016) The Vertebral Fracture Cascade: etiology and clinical implications. J Clin Densitom 19(1):29-34. https://doi.org/10. 1016/j.jocd.2015.08.007

38. Roux C, Fechtenbaum J, Kolta S, Briot K, Girard M (2007) Mild prevalent and incident vertebral fractures are risk factors for new fractures. Osteoporos Int 18(12):1617-1624. https://doi.org/10. 1007/s00198-007-0413-1

39. Fink HA, Litwack-Harrison S, Ensrud KE, Shen J, Schousboe JT, Cawthon PM, Cauley JA, Lane NE, Taylor BC, Barrett-Connor E, Kado DM, Cummings SR, Marshall LM, Osteoporotic Fractures in Men Study G (2017) Association of Incident, clinically undiagnosed radiographic vertebral fractures with follow-up back pain symptoms in older men: the osteoporotic fractures in men (MrOS) study. J bone miner res. https://doi.org/10.1002/jbmr.3215

40. Diaz-Arribas MJ, Fernandez-Serrano M, Royuela A, Kovacs FM, Gallego-Izquierdo T, Ramos-Sanchez M, Llorca-Palomera R, PardoHervas P, Martin-Pariente OS (2017) Minimal clinically important difference in quality of life for patients with low back pain. Spine (Phila Pa 1976). https://doi.org/10.1097/BRS.0000000000002298 